\title{
Retraction Note: Optimized extraction, composition, antioxidant and antimicrobial activities of exo and intracellular polysaccharides from submerged culture of Cordyceps cicadae
}

Sapan Kumar Sharma ${ }^{1 *}$, Nandini Gautam² ${ }^{2}$ and Narender Singh Atri $^{3}$

\section{Retraction Note}

The editor has retracted this article [1] due to overlap with a previously published article [2]. Both articles also appear to use the same image representing different fungal mycelial growths. S.K. Sharma and N.S. Atri do not agree to this retraction. N. Gautam has not responded to correspondence from the editor about this retraction.

\section{Author details}

'Department of Plant Pathology, CSK, Himachal Pradesh Agriculture University, Palampur 176 062, India. ${ }^{2}$ Centre for Environment Science and Technology, School of Environmental and Earth Sciences, Central University of Punjab, Bathinda 151 001, India. ${ }^{3}$ Department of Botany, Punjabi University Patiala, Patiala, Punjab 147 002, India.

Published online: 16 October 2018

\section{References}

1. Sharma SK, Gautam N, Atri NS. Optimized extraction, composition,

antioxidant and antimicrobial activities of exo and intracellular polysaccharides from submerged culture of Cordyceps cicadae. BMC Complement Altern Med. 2015;15:446. https://doi.org/10.1186/s12906-0150967-y.

2. Sharma SK, Gautam N, Atri NS. Optimization, composition, and antioxidant activities of exo- and intracellular polysaccharides in submerged culture of Cordyceps gracilis (Grev.) Durieu \& Mont. Evid Based Complement Alternat Med. 2015;2015:8. https://doi.org/10.1155/2015/462864.

\footnotetext{
* Correspondence: sharmasapan84@yahoo.in

1 Department of Plant Pathology, CSK, Himachal Pradesh Agriculture

University, Palampur 176 062, India
} 